\title{
The International Regime model
}

In the preceding chapters, we have analysed the climate strategy choices of the oil industry as a function of company-specific factors (the CA model analysed in chapter 4 ) and of factors linked to the domestic political context in the home-base countries of the companies (the DP model analysed in chapter 5). These models have provided us with some answers as to why the climate strategies of the oil companies differ, but have left other questions unanswered. In particular, we do not have a good understanding of Shell's turnabout from a reactive to a proactive company. Additionally, it is difficult to understand on the basis of the CA and DP models why ExxonMobil did not modify its reactive strategy in the four-year period from the US's signing of the Kyoto Protocol until Bush Jr was elected president.

In this chapter, we shift our focus from the domestic to the international level. To what extent can the international climate regime explain the strategies chosen by the oil industry? Climate change is a global problem partly caused by global actors operating within the framework of international institutions. It is thus natural to move beyond the study of single companies within single states to get a comprehensive understanding of corporate climate strategies. Accordingly, the International Regime (IR) model is concerned with corporate alliances across states and how such alliances relate to international regimes over time.

Recalling our propositions discussed in chapter 2, we assume that corporate climate strategy is likely to be formed through the two-way influence between regimes and industry. This approach permits a stronger focus on changes in corporate strategies over 
time. The argument is straightforward: if industry determines joint international climate commitments, the regime is unlikely to affect industry strategy. Conversely, if industry exerts little influence over joint international climate commitments, the regime is likely to affect industry strategies. More specifically, we assume that to the extent that a reactive industry exerts a strong influence on the international climate regime, a reactive strategy is likely to persist. The international climate regime provides industry with the opportunity of exercising influence far beyond single home countries. The regime channel is particularly important for large multinational companies operating all over the world. Our analysis of the influence exerted by a reactive industry on joint commitments in the climate regime is based on three assumptions. First, we assume that the influence of target groups tends to increase the more cohesive their strategies are. Second, influence is likely to depend on the strength of counterbalancing forces such as ENGOs. Third, we assume that influence will increase the more access industry has to decision-making processes and the fewer actors need to be persuaded to block collective decisions. The last point is related to the decision procedures applied by the regime.

To the extent that a reactive industry exerts a weak influence on the international climate regime, we assume that the industry is more likely to shift towards a more a proactive climate strategy as a response to regime development. In contrast to the policy of home-base countries, a progressing international regime carries the potential of affecting multinational companies all over the world. The impact of the climate regime on strategy choice is analysed in terms of three causal pathways: knowledge, pressure and opportunities.

\section{From Rio to Kyoto: corporate influence on the climate regime}

It is difficult to separate the influence of one corporation in particular at the international level since companies tend to coordinate their positions within industry organisations to match the scope of the international regimes. We will thus explore the influence of the fossil-fuel lobby in general, with a particular focus on ExxonMobil and Shell. To measure the influence of the fossil-fuel lobby, we proceed in two steps. First, we deploy the criterion of goal attainment to analyse the match between industry positions 
and joint international commitments. Goal attainment in this context refers to the extent to which the industry succeeded in achieving its goal of preventing ambitious GHG emissions reduction targets from entering the joint international climate commitments. We focus on the UNFCCC, the Kyoto Protocol, and the post-Kyoto process leading up to the US withdrawal from the Kyoto agreement. Second, we search for observable influence within the two most important actors that to a large extent have determined the international commitments: the US and the EU. Notice that focus on the US is changed from domestic climate policy (chapter 5) to the development of positions in international negotiations. It is also important to note the dual role of the EU in this context. On the one hand, the EU is an actor within the framework of the international climate regime. On the other hand, the EU constitutes in itself a regime, with an increasingly more ambitious approach to the climate problem. While the EU generally is clearly different from international regimes with regard to its scope, depth, nature and competence, EU environmental policies in specific issue areas, such as climate change, face many of the same implementation challenges as international regimes (Skjærseth and Wettestad, 2002).

\section{Corporate influence on the UNFCCC}

Unity, mismatch and divergence characterise the past decade of the relationship between the climate regime and fossil-fuel industry interests. In the prelude to the UNFCCC, the fossil-fuel lobby, including ExxonMobil and Shell, was unified in its opposition to binding and specific international climate targets. All major oil companies took the position that action on global warming could be damaging to their economic interests. Moreover, the fossil-fuel lobby had a near monopoly over the entire business and industry perspective:

In the early 1990s, the idea of significantly limiting greenhouse gas emissions would have been opposed by almost all the major industries on the planet: the fossil fuel industries, 'from production to the pump', along with most manufacturing, processing and automobile industries. The rest of the corporate world would at best have been indifferent, with the almost trivial exception of the nascent energy efficiency and non-fossil energy industries. (Grubb et al., 1999: 257) 
Industry did not necessarily reject the possibility of an emerging climate-change problem, but industry organisations emphasised 'no regrets' measures (measures that were already justified on other grounds), national flexibility and voluntary measures. Moreover, industry placed emphasis on the global nature of the problem and problem solving 'abroad' in less developed countries and those with economies in transition. This focus would distract attention from domestic regulation. For example, the Union of Industrial and Employers' Confederation of Europe (UNICE) emphasised assistance to eastern European countries as a core strategy towards combating climate change (UNICE, 1991).

Until 1992, the fossil-fuel industry, particularly in the US, had a good grip on the international process. The UNFCCC was roughly in line with the interests of the fossil-fuel lobby and the oil industry. The API, for instance, was pleased with the outcome. ${ }^{1}$ It did not include any binding 'targets and timetables' for emissions reductions, and it did not restrict the parties' choice of policy instruments. In essence, the Convention did not exert pressure or create significant market opportunities for industry. It did, however, place the responsibility for the climate problem and its solution on developed countries, and established an institutional framework for reporting action as well as guiding the next steps. The UNFCCC was thus designed in line with the notion that institutionalised international cooperation gathers momentum through a 'snowball' effect generating positive feedback and facilitating further steps. As noted in chapter 2 , this process becomes more likely when initial institutional arrangements have a narrow scope, include lenient commitments and possess institutional feedback mechanisms that encourage dynamic development. These institutional qualities contained the seeds for progressing beyond the control of the fossil fuel industry.

Since 1989, the EU had worked for $\mathrm{CO}_{2}$ stabilisation by means of firm reduction targets and timetables. The EU Commission aimed at taking a leading role in Rio by developing a climate 'package' containing a carbon/energy tax. While the EU-led initiative to set firm targets and timetables for $\mathrm{CO}_{2}$ emissions went beyond the interests of the European fossil-fuel industry, the struggle within the EU prior to the Rio Conference provides a clear example of European industry influence. In general, business 
influence on EU environmental policy is substantial in all phases of the policy-making process (Grant et al., 2000). Depending on the decision-making procedures applied, EU industry has two main channels at its disposal: indirectly through domestic channels to national positions in the Council of Ministers, or directly through lobbying the Commission or Parliament. According to many observers, the carbon/energy tax proposed in 1991 was made subject to the most ferocious lobbying ever seen in Brussels (Skjærseth, 1994; see also Ikwue and Skea, 1994).

UNICE - the voice of European business at present representing 34 industry and employers' federations from 27 European countries - argued that the tax proposal ran completely counter to the need for concerted international action and would lead to difficulties for employment and competition (UNICE, 1991). While UNICE offered alternative climate strategies, EUROPIA played even tougher by expressing the 'strongest reservation concerning the creation of any new tax on oil products'. ${ }^{2}$ Fierce industry lobbying led to the inclusion of tax conditionality, meaning that the tax would not be implemented if other OECD countries did not follow suit. This contributed to the killing of the tax and consequently to the crippling of EU leadership ambitions in Rio (Skjærseth, 1994; see also Newell, 2000). In the end, however, it was the member states that sank the tax proposal. Some countries argued that it did not go far enough. The Danes in particular said that it could not pass with the conditionality clause included. Other member states claimed that it was going too far, at too early a stage. The UK in particular opposed the use of fiscal mechanisms at the EU level as a matter of principle. Compared to the way the US fossil-fuel lobby killed the BTU tax proposed by the Clinton-Gore administration four years later (see chapter 5), the dispute about the EU carbon/energy tax also demonstrates the limits of industry influence within the EU.

Nevertheless, it was the US that determined the outcome of the UNFCCC: 'It was solely as a result of U.S. adamancy even in the face of complete isolation that the final text of the UN Framework Convention on Climate change (UNFCCC) contains only ambiguous language with regard to commitments' (Agrawala and Andresen, 1999: 461). Moreover, we have strong indications that industry played a key role in fuelling this adamancy prior to 1992. As discussed in chapter 5, the US plural- 
ist political system provides ample room for interest groups to lobby for their interests in the development of national energy and climate policy. In the US, the domestic channel appears equally important for affecting international climate policies. The US fossil-fuel industry, in alliance with President George Bush, the Republican administration, and GHG sceptic chief of staff John Sununu influenced the mandate given to the US climate delegation (Newell, 2000). As early as 1989, the US delegation had been instructed to work for a weak framework convention on climate change through the United Nations Conference on Environment and Development (UNCED) process. According to Newell, 'the wording of the memo suggests that the negotiating space available to the US had been predetermined by a concern not to damage the interests of the fossil fuel industries' (Newell, 2000: 103).

\section{Changes in corporate influence from Rio to Kyoto}

Five years later, in December 1997, the Kyoto Protocol was adopted. The Protocol departed significantly from the interests of the fossil-fuel lobby and the oil industry in at least two ways: first, by requiring specific and mandatory reduction objectives within specific time frames ('targets and timetables'), and second, by exempting developing countries from any commitments. While Kyoto went far beyond the interests of the fossil-fuel lobby, it nevertheless fell short of the wishes of the green movement (Corell and Betsill, 2001). According to Grubb, 'the agreement was struck in the face of strong opposition from powerful industries, particularly in the United States, and with a set of flexibilities that were opposed by almost all environmental NGOs. It was very much an agreement struck by governments' (Grubb et al., 1999: 257).

Based on the UNFCCC, the Kyoto Protocol represented a visible sign of regime 'maturation' beyond the control of the fossil-fuel industry. With its commitment period from 2008 to 2012, the Protocol shaped expectations that could not be ignored by the fossil-fuel industry. In order to understand why ExxonMobil and Shell interpreted these expectations so differently, we have to understand how the driving forces underlying the match between industry interests and joint international climate commitments changed from 1992 to 1997. We will 
explore three propositions: (1) the international fossil-fuel lobby had dissolved and lost its influence prior to Kyoto; (2) the influence of the green movement had increased and thus outweighed the fossil-fuel lobby; and (3) changes in decision-making procedures and access served to reduce the power of the fossil-fuel lobby to influence decision-making.

The fossil-fuel lobby The fossil fuel lobby is mainly represented through the GCC, which was established in 1989 and is characterised by many observers as the most powerful corporate lobby organisation in climate policy (Raustiala, 2001). The organisation represented a large share of US GDP. More than 50 big US and European companies based in the US participated, representing virtually every sector of US industry, including trade associations and the oil, coal, utility, chemicals and auto industries. ExxonMobil has been very active in the organisation. ${ }^{3}$ The GCC spent a serious amount of money to convince policy-makers that proposals to limit $\mathrm{CO}_{2}$ emissions are 'premature and are not justified by the state of scientific knowledge or the economic risks they create' (Levy, 1997:58). For example, the GCC sponsored a study concluding that the Kyoto Protocol would cost the US over 2.4 million jobs and reduce the GDP by US $\$ 300$ billion annually (Carpenter, 2001).

After binding targets and timetables were prevented from entering the UNFCCC in 1992, the US fossil-fuel lobby continued to fight against them. US industry was also able to stop the BTU tax proposed by the Clinton-Gore administration in the Senate Finance Committee in 1993. At the first Conference of the Parties in 1995, the US agreed to the 'Berlin Mandate', declaring that non-binding commitments for developed countries were inadequate and that no new commitments would be imposed on developing countries. The latter had been approved by Vice-President Gore and was met with sharp criticism from industry lobbyists and the Republican Congress, subsequently forcing the administration to retract its position (Agrawala and Andresen, 1999).

In the period leading up to Kyoto, lobby activities intensified in the US. For example, the GCC sponsored a US\$13 million television campaign saying that the price of petrol would increase by 50 cents per gallon if Kyoto timetables were implemented. ${ }^{4}$ Before the final negotiations took place in Kyoto, the Senate 
delivered a clear message to the Clinton-Gore administration about its viewpoint: in a unanimous $95-0$ vote, the Senate stated that it would not accept several of the conditions that are now codified in the Kyoto agreement. In July 1997 - five months before the Kyoto meeting - the Senate voted against any treaty that would exempt developing countries from legally binding commitments and imply higher energy costs, particularly on petrol (Byrd/Hagel resolution). For the Kyoto Protocol to be ratified by the US Senate, and thus become American law, it must receive 67 out of 100 senatorial votes. This non-partisan congressional resistance has been directly related to the powerful lobbyists representing the GCC in general, and the coal and oil industry in particular (Newell, 2000; Agrawala and Andresen, 2001). Since the Senate would have to ratify the Kyoto Protocol, the Byrd/Hagel resolution tied the hands of US negotiators in Kyoto and subsequently led the fossil-fuel lobby to believe that the Protocol would never be ratified in the US. ${ }^{5}$

In 2000, it was difficult to find any major US company that supported the Kyoto Protocol (Skodvin and Skjærseth, 2001). ExxonMobil, API and the GCC viewed the Protocol as 'dead on arrival', independent of the upcoming presidential election in 2000. The perception of the situation of these organisations before the 2000 election was as follows: the Democratic candidate, Vice-President Al Gore, would probably put all his political weight into persuading the Senate. However, Gore already had a low standing in the Senate and would in any case face considerable opposition. The Republican candidate, George W. Bush Jr, would have a higher standing in the Senate, but would not push for ratification. ${ }^{6}$

ExxonMobil has in fact been convinced that the US would never ratify the Protocol, and the company has firmly claimed that a 'Plan B' in case of ratification has never been needed. ${ }^{7}$ The GCC also threatened lawsuits against legislation necessary to implement the Kyoto Protocol. The prospect of lengthy legal processes added to ExxonMobil's conviction that the Protocol would never become a reality in the US. The Protocol required the US to reduce its emissions by 7 per cent compared to 1990 levels within the period 2008-2012. Since 1990, US emissions have increased by over 14 per cent, and they are expected to increase by at least 1 per cent each year for the next decade. This means 
that the emissions will have to be reduced by more than 30 per cent during the agreement period. In principle, the Kyoto Protocol allows for emissions trading, but many doubted the political realism of the US becoming a major buyer of quotas in Russia. Russia's underground economy and poor overview of its own emissions would create serious problems for this kind of solution. Reductions of the order of 30 per cent by 2008-2012 seemed unlikely without large-scale investment in Russian quotas and powerful domestic climate policy instruments and measures. The US has no tradition of signing international treaties without a fair chance of compliance. If the US had ratified the Kyoto Protocol, the 2008-2012 targets would still be out of reach because of the need for dramatic domestic cutbacks combined with anticipated time-consuming legal action initiated by industry and environmental groups against the EPA. With the benefit of hindsight, the US withdrawal a few years later came as no surprise.

These domestic concerns did not, however, stop the international ambitions of the Clinton-Gore administration. The US position in the Kyoto negotiations was revealed shortly before the Kyoto summit in December 1997: President Clinton aimed to return GHG emissions to 1990 levels by 2008-2012, and participation by developing countries was set as a precondition for US agreement. The GCC and the API lobbied hard before Kyoto, and the API believed that it had succeeded in influencing the US position even though the stabilisation target went beyond API interests. ${ }^{8}$ Meanwhile, the EU had agreed on an internal burdensharing scheme and had proposed to cut emissions by 15 per cent from 1990 levels. Negotiations in Kyoto thus reached a deadlock. In this situation, Vice-President Gore made his famous 16-hour visit to Kyoto, where he called upon US negotiators to increase negotiation flexibility. The next day, the chief US negotiator signalled his willingness to negotiate emissions cuts that went beyond stabilisation (Agrawala and Andresen, 1999).

The EU position indicated that the European fossil-fuel industry had lost influence within the EU. European industry had been most concerned with the EU carbon/energy tax and consequences for European competitiveness. The shift in focus from taxes to burden-sharing, renwables and flexible mechanisms took care of the most controversial aspect of EU climate policy. UNICE, however, agreed with the US oil lobby that developing countries 
should participate in an effort to combat climate change. Moreover, UNICE has always stated that EU climate policy should be made conditional upon similar action taken by major trading partners (UNICE, 2000). The Kyoto Protocol, therefore, also failed to secure an international solution in line with the wishes of European industry, and it would be an exaggeration to say that the European fossil-fuel industry applauded the adoption of the agreement. European oil giants, however, did extend a cautious welcome to the Protocol, which may be seen as an early warning of the changes that were to come within the oil lobby.

Prior to the Kyoto meeting, the oil lobby was weakened by an emerging disintegration with BP's exit from the GCC in 1996, but the major changes in the strength of the coalition appeared after the adoption of the Kyoto Protocol: Shell followed BP in 1998. The exits of the European oil majors also seem to have set off a reaction in US companies: in late 1999, the Ford Motor Company withdrew from the GCC, followed by DaimlerChrysler, General Motors and Texaco. It is important to note, however, that even though the US companies could no longer accept the aggressive anti-climate stance of the GCC, they remained firmly opposed to the Kyoto Protocol, in contrast to the European oil companies (Skodvin and Skjærseth, 2001).

The GCC was 'deactivated' in 2002 - after 13 years in operation. According to the GCC itself, the group 'served its purpose by contributing to a new national approach to global warming', i.e. the US withdrawal from the Kyoto Protocol. Malicious tongues would say that the GCC has moved into the White House. However, another, and perhaps more important, cause is probably declining support within the business community, since the Protocol is still alive and future US participation cannot be excluded. ${ }^{9}$

Even though the main instrument for orchestrating the fossilfuel industry opposition to GHG regulations - the GCC - did show signs of an emerging disintegration, there were no major changes in the alliance until after the adoption of the Kyoto Protocol. The EU position and the shift in focus away from taxes, however, shed light on the softening of the European industry position before Kyoto. The US fossil-fuel industry, on the other hand, remained unified and firmly opposed to binding targets and timetables. Moreover, the Byrd/Hagel resolution explains why 
ExxonMobil was convinced that the Kyoto Protocol would never be ratified in the US. Since the US occupied a pivotal role in the climate regime, the county's fossil-fuel lobby also believed that a US withdrawal would put the Protocol out of action. Nevertheless, the change in match between fossil-fuel industry interests and joint commitments can only to a limited extend be ascribed to a weakening fossil-fuel lobby. On this basis, we would expect that other conditions had changed prior to 1997.

Counterbalancing forces: the green movement Governments, target groups and ENGOs constitute the most important triangle of stakeholders present in the climate change process. ENGOs tend to represent a significant counterbalancing force to target groups, sometimes directly influencing their strategies as well as the policy of governments (see chapter 5). It is reasonable to assume that the more effective resistance to business strategies in this triangle of interests, the less industry influence can be expected. In contrast to chapter 5, we shall look specifically at whether changes in the influence of ENGOs over time shed light on changes in industry influence on joint climate commitments.

On the one hand, most analysts seem to agree that ENGOs have had little direct influence on the climate-change negotiations (Newell, 2000; Betsill and Corell, 2001). On the other hand, there seems to be an equally robust agreement that ENGOs have played an important indirect role by shaping the agenda, activating social demands and creating expectations. Carpenter (2001:320) even argues that ENGOs have always represented a formidable force in the climate-change negotiations. One major reason for these somewhat contradictory observations is that ENGOs' influence is extremely hard to measure. Also, they represent a diverse group that pursues a variety of goals and priorities. With these caveats in mind, we explore changes in ENGO influence in three decision-making arenas: the international negotiation process, and climate policy-making processes in the US and the EU.

In the international negotiation process, the final agreements do not reflect ENGO goals. Even though ENGOs constitute a diversified group, they were unified in their dissatisfaction particularly with the UNFCCC, but also with the Kyoto Protocol. Most ENGOs would agree that the Kyoto targets are too modest and that stronger review and compliance mechanisms are required. In 
1997, with the slogan 'trading pollution is no solution', they also opposed emissions trading while they remained divided over the CDM, linked to forests and sinks. For example, many ENGOs strongly oppose the inclusion of any projects concerning biological sinks in the CDM, while other groups strongly support the inclusion of sinks offered by forest conservation and restoration. ${ }^{10}$ As we shall see below, the ENGO position on emissions trading has changed significantly.

Lack of direct influence can hardly be traced back to lack of participation at the international level. The number of all types of NGOs (including business and industry groups and ENGOs) accredited as observers more than doubled between 1992 and 2000 (Carpenter, 2001). More than 40 ENGOs sent representatives to at least two of the nine sessions of the Ad Hoc Group on the Berlin Mandate (AGBM) and on average more than 100 ENGO representatives were at each session (Corell and Betsill, 2001). However, ENGOs were outnumbered by industry: at AGBM-6, there were about 35 business organisations with some 150 representatives, compared to 25 ENGOs with about 90 representatives (Raustiala, 2001). At these sessions, ENGOs tried to coordinate their strategies under the Climate Action Network (CAN). Established in 1989, CAN is an umbrella organisation comprising most international ENGOs that are active on climatechange issues in central and eastern Europe, Latin America, South East Asia, South Asia, Africa, the US and Europe. CAN Europe (Climate Network Europe, or CNE) alone enjoys the membership of 85 European ENGOs. At the AGBM and Conference of the Parties (COP) meetings, CAN members held seminars, interacted with the media and lobbied delegates. ${ }^{11}$

Despite increased participation, the influence of ENGOs appears to have declined over time. First, in the late 1980s, ENGOs were very influential in setting the agenda of climate change as an issue that had to be addressed. At that time, most industry organisations had limited knowledge of both the problem and the consequences of problem solving. ENGOs actually dominated the ranks of NGOs in the emerging climate regime, but have faced increased opposition from business and industry groups over time. Second, ENGOs have become increasingly diversified (Carpenter, 2001). An increasing inability to 'speak with one voice' has constrained their power to influence 
negotiation processes. Third, while ENGOs were permitted access to most negotiating arenas, they were excluded from informal meetings where the real negotiations took place. From the INC meetings during the initial phases of the process to the Kyoto negotiations, ENGOs were excluded from closed-door sessions (Newell, 2000). The most effective channel for ENGOs as well as for the fossil-fuel lobby, however, is the domestic.

In the US, ENGOs were instrumental in putting climate change on the political agenda in the late 1980s. In 1988, the first element of a climate regime emerged at an international conference in Toronto calling for a 20 per cent cut in $\mathrm{CO}_{2}$ emissions by 2005. US environmental groups participated at this conference and used the international process to market the threat of climate change to domestic actors (Agrawala and Andresen, 1999). This happened before the US fossil-fuel industry had mobilised and formed the GCC. Moreover, it happened concurrently with the heat waves and drought that hit North America in the summer of 1988. According to Agrawala and Andresen (1999), however, the influence of US ENGOs was significantly reduced as the international process leading up to the UNFCCC became more institutionalised and the fossil-fuel lobby grew in power. These researchers further argue that US ENGOs today function primarily as disseminators of information on international negotiations and assessments. This is supported by the fact that GreenpeaceUS resigned from its efforts to lobby for US ratification even before Bush Jr was elected president.

The strategies chosen by the environmental groups may also have undermined their influence when the fossil-fuel industry mobilised: US ENGOs adopted a climate-change strategy based on cooperation with industry (Eikeland, 1993). Newell (2000) argues that the low influence of ENGOs in US climate policy is related more to strong opponents than to lack of access to decision-making processes. Indications of real influence with possible consequences for joint commitments are mainly related to the creation of public expectations that have contributed to participation at a high level. There seems to be a quite robust pattern indicating that the green movement in North America has experienced a decline in influence on US climate policy.

In the $E U$, few green organisations are permanently represented in Brussels. However, ENGOs are represented by eight 
large umbrella groups such as the CNE, Greenpeace and the European Environment Bureau (EEB). There are fewer people representing environmental interests in Brussels as a whole than there are representing business interests in the UNICE secretariat alone. While noting that industry groups are generally in a stronger position within the EU policy-making process, Grant et al. (2000) also argue that the supranational EU system provides ENGOs with some specific agenda-setting opportunities. Of particular importance is the fact that the environment directorate in the Commission needs ENGOs to do its job. The small size of the Commission makes it dependent on ENGO sources for advice. The Commission contributes financial support to ENGOs, and the EEB was founded by the Commission as a counterbalancing force to industry groups. The symbiotic relationship between the environment directorate and ENGOs has also been reflected in the strategies of the European ENGOs: they seek to strengthen and expand proposed targets and measures, and they support legislative proposals from the Commission against the Council and business interests (Skjærseth, 1994).

The problem for the ENGOs, however, is that industry tends to make alliances with more powerful parts of the Commission. The dispute about the EU carbon/energy tax is quite illustrative. The driving force within the Commission was an alliance between the directorates for environment and energy. This was supported by ENGOs such as Greenpeace and Friends of the Earth (FoE). For example, FoE presented a position paper defending the tax proposal against industry. ${ }^{12}$ On the other side, the industry allied with the most 'business-friendly' and powerful directorates responsible for economics and the internal market. This alliance paved the way for the principle of conditionality (Skjærseth, 1994).

Significant changes have occurred since the European ENGOs were defeated over the carbon/energy tax proposal. While the US concept of emissions trading was met with a wall of ENGO protests in Kyoto, emissions trading has now been accepted by European green organisations. CNE, for instance, 'regards the Directive [the EU directive on emissions trading] as a potentially useful proposal' and argues that it 'offers the potential for significant emissions reductions within the European Union, [although it] contains a number of actual and potential weaknesses'. ${ }^{13} \mathrm{CNE}$ 
argues that the EU scheme should be kept separate from Kyoto trading in order to exclude 'hot air' and sinks. A more fundamental change is perhaps the emerging agreement and cooperation between European business, industry and ENGOs, demonstrated particularly in relation to the development of a scheme for emissions trading within the EU. In essence, while EU climate-change policy in the early 1990s pitted all stakeholders against each other over an EU proposal (the carbon/energy tax), a US proposal (emissions trading) unified the same stakeholders in 2001.

While ENGOs certainly have been present in the decisionmaking process at the international level as well as in the US and $\mathrm{EU}$, there are no indications that their influence has increased over time. On the contrary, to the extent that there has been a change in ENGO influence, it is in the direction of a decrease rather than an increase. Thus, the fossil-fuel industry has not lost control over the international negotiations due to increased ENGO influence. Change in the influence of the environmental movement can hardly explain the changes in the influence of the fossil-fuel lobby from the UNFCCC to the Kyoto Protocol.

Access and decision-making procedures In general, non-state actors have had good access to the international negotiation process, although there are indications that the scope for influencing the process appears to have been higher in the run-up to the UNFCCC than to the Kyoto meeting (Corell and Betsill, 2001). As noted above, however, non-state actors have regularly been excluded from participation at informal meetings. Particularly during the final negotiations of the Kyoto Protocol, negotiation meetings were increasingly closed for non-state delegates. Thus, while there are some indications that there were changes in nonstate actors' access to decision-making processes at the international level between 1992 and 1997, these minor shifts cannot fully account for the significant alteration in industry influence during this period. Access to the international meetings is not perceived as critical by the fossil-fuel lobby. The API estimates the relative importance of domestic versus international channels as 70 to $30 .{ }^{14}$

However, the US oil industry experienced a temporary change in the US administration that implied less access for the industry to relevant decision-making processes at home. In general, there 
was little cooperation and consultation between the Clinton-Gore administration and fossil-fuel industry groups before the Kyoto negotiations. In particular, the US oil industry was excluded. The API's perception is that the Clinton-Gore administration showed no interest in cooperating with 'Big Oil'. ${ }^{15}$ API and other industry interests met with Gore in Kyoto but were unable to change his view. ${ }^{16}$ Vice-President Gore's call for increased negotiation flexibility in Kyoto thus prevented the fossil-fuel industry, in alliance with Congress, from inflicting its interests upon the rest of the world.

US flexibility generated concessions from other countries leading to the consensus agreement on the Kyoto Protocol and the US commitment to reduce GHG emissions by 7 per cent from 1990 levels by 2008-2012 (Agrawala and Andresen, 1999). The US also relented on the issue of participation by developing countries, but won a number of other concessions, particularly from the EU. ${ }^{17}$ Ironically, the Kyoto Protocol, with its emphasis on sinks and flexibility mechanisms, is essentially a US construction designed to sugar the pill for US industry. ${ }^{18}$ In the event, however, the US commitment to Kyoto represented only a temporary loss of US industry influence. The industry maintained a strong influence in Congress through the Byrd/Hagel resolution.

For the Kyoto Protocol to enter into force it must be ratified by 55 countries representing at least 55 per cent of global $\mathrm{CO}_{2}$ emissions in 1990. The US is responsible for about one quarter of the global emissions of GHGs and is thus a key actor in international climate politics. The Protocol can enter into force even without an American ratification, but the central role of the US implied that a Kyoto Protocol without it was not seen as very realistic. Thus, US multinationals with significant activities in Europe still had a fair chance of exercising influence beyond their home-base country.

In addition to access, decision rules represent another important determinant for industry influence. The climate regime itself has been based on consensus. All decisions under the Convention need to be made by consensus since it has been impossible to adopt rules of procedure. This implies that the US fossil-fuel industry nearly blocked the adoption of the Kyoto Protocol through the Byrd/Hagel resolution.

Within the EU, an institutional development with significant 
implications for European businesses' influence over EU climate policy has taken place. A development towards an increased use of qualified majority voting in the Council of Ministers has by itself affected the organisation of the EU lobby. Since the Single European Act of 1987, decisions related to the internal market have been based on Article 100a, which requires a qualified majority. This implies that member states can be outvoted in Council, and consequently that the domestic channel is no longer sufficient for lobby organisations. As a consequence, the number of lobby organisations representing business and industry in Brussels rose dramatically, from about 600 in 1986 to almost 3,000 in 1990 (Skjærseth, 1994). Thus, organised lobbying of the EU Commission is a more recent phenomenon in the EU than in the US.

Complex decision-making procedures have evolved in the EU whereby the European Parliament has been given more power and there is greater use of majority voting within the Council of Ministers. The European Parliament is widely perceived as the 'greenest' of the EU institutions. The 1992 Treaty of Maastricht extended the use of majority voting so that it became the rule on environmental matters. Fiscal measures, however, were excepted from this procedure. The proposed carbon/energy tax would thus require consensus, meaning that European businesses would have to persuade only one state to block the proposal. The 1997 Amsterdam Treaty broadened the application of the co-decision procedure to cover directives adopted on the basis of the 'environmental' paragraph 130 s, hence increasing the decision-making role of the Parliament further. These institutional changes and the shift in focus away from taxes prior to Kyoto thus narrowed the scope available for European business organisations to influence EU climate policy, with a softened industry opposition as a result. Relevant EU directives since Kyoto have been proposed on the basis of qualified majority. For example, the EU directive on a framework for GHG emissions trading is proposed according to Article 175 (1), which requires a qualified majority (see below).

\section{Summary: corporate influence}

The US fossil-fuel industry, with ExxonMobil in the lead, did not lose influence on joint climate commitments due to a weakening of the fossil-fuel lobby or stronger counterbalancing forces in the 
green movement. If that had been the case, a company like ExxonMobil would have had to reconsider its reactive climate strategy. While the fossil-fuel lobby does show signs of an emerging weakening during the period immediately preceding the adoption of the Kyoto Protocol, the major changes in the strength of the fossil-fuel coalition occurred after the adoption of the Kyoto agreement. Moreover, even the US multinationals that left the GCC continued to oppose the Kyoto Protocol. Similarly, while the environmental movement certainly has been very much present in the development of climate policy both at the international level and in decision-making processes in the US and the $\mathrm{EU}$, its influence has decreased rather than increased during the period from 1992 to 1997.

Within the EU, a permanent change in the decision-making procedures took place with the increased use of decision rules based on a qualified majority and more involvement by the Parliament in decision-making. This change implied that it was no longer sufficient for the industry to persuade only one member state to bar unwanted policies. To influence decision-making, the reactive industry had to convince a majority of the member states, which is a more difficult task. In addition, the change in EU climate policy from taxes to burden-sharing, renewables and flexible mechanisms reduced European companies' resistance to GHG measures. Also, BP's exit from the GCC before the adoption of the Kyoto Protocol weakened the oil lobby, although the major change in the cohesion of the oil lobby took place after the adoption of the Protocol. Thus, the climate policy of the EU acquired its own dynamic largely beyond the control of big European multinationals like Shell.

In the US, the fossil-fuel industry was excluded from the decision-making process of the Clinton-Gore administration in the period immediately preceding the Kyoto negotiations. In contrast to the changes that occurred in the decision-making procedures in the EU, however, this loss of influence was only temporary. The Byrd/Hagel resolution implied that the industry still exerted a strong influence in Congress, which had the final word concerning US ratification of the Kyoto Protocol. Here, we also find an important reason why ExxonMobil did not modify its climate strategy as a consequence of the US signing of the Kyoto Protocol: ExxonMobil and the rest of the US fossil-fuel industry were 
convinced that the Kyoto Protocol would never be ratified in the US, and as a consequence probably not ratified at all. A Kyoto Protocol in force without the United States could not be excluded, but would represent a dramatic weakening of the climate regime. In essence, the US fossil-fuel industry maintained strong influence over the climate regime in either case.

The Kyoto Protocol departed significantly from the interests of the fossil-fuel industry. This development was apparently caused by an evolving regime set in motion by the UNFCCC. The US fossil-fuel industry in particular made intense efforts to block this process through domestic channels, but did not succeed. However, this industry knew it could block US ratification at a later stage. Significant changes in the strategies of the industry occurred after Kyoto and mainly in Europe.

\section{From Kyoto to Marrakech: regime impact on corporate strategy choice}

As it turned out, the adoption of the Kyoto Protocol became the precursor to an emerging divide between Europe and the US both in policy measures and in fossil-fuel industry strategy.

In this section, we analyse the extent to which the changes in corporate strategies that took place after the adoption of the Kyoto Protocol can be traced back to changes in the international climate regime. We home in on the emerging division between the international climate regime and the EU and explore the causal relationship between regime features and corporate strategies. The discussion is organised around the three causal pathways through which international regimes can affect corporate strategy that were discussed in chapter 2: knowledge, pressure and opportunity.

\section{Knowledge}

The scientific uncertainty argument has repeatedly been used within the corporate fossil-fuel lobby. ExxonMobil builds its reactive climate strategy on the assumption that the international climate regime is based on 'bad' science, while Shell accepts the IPCC's definition of the problem. The assumptions put forth in chapter 2 were that differences along this dimension might result from differences in corporate access to the IPCC process. 
Alternatively, there might be differences in the companies' receptiveness to the information provided.

The main institution for the generation of a common understanding of the nature of the climate problem is the IPCC, established under the auspices of the United Nations Environment Programme (UNEP) and the World Meteorological Organisation (WMO) in 1988. The purpose of the body is to give all concerned parties - governmental as well as non-governmental - equal access to the most up-to-date, state-of-the-art scientific knowledge on climate change. The IPCC thus has an independent institutional platform, separate from the political bodies of the climate regime, which are organised directly under the UN General Assembly (see Skodvin, 2000a, 2000b). With its intergovernmental status, however, the IPCC is nevertheless a hybrid organisation operating at the interface of science and politics. This status implies that the body is open to participation by all UN member states.

With its independent institutional platform, the IPCC is neither under the direct control of the political bodies of the climate regime, nor has any channels for direct input to the bodies where political deliberations take place. One of its main functions, however, is to develop - through negotiations between scientists and government officials - a common understanding of the nature and magnitude of the climate problem and possible solutions (Skodvin, 2000a). This implies that the IPCC can affect climate policy in at least two important respects. Its work can have an impact at the national level, to the extent that national decisionmakers accept IPCC conclusions as valid and act upon them in their design of national climate policies. The IPCC can also have an impact at the international level, to the extent that it succeeds in developing a problem definition, agreed upon by parties representing conflicting interests, which thus can constitute a common framework of understanding upon which international climate policies can be based. Thus, even though the institutional set-up of the IPCC implies that it does not have direct 'access' to policymaking, its work and the associated process constitute an important part of the framework conditions within which the oil industry develops its climate strategy (for a more detailed analysis of the IPCC see, for instance, Agrawala, 1998a, 1998b; Skodvin, 2000a, 2000b). 
The IPCC has issued three assessment reports - in 1990, 1995 and 2001 - in addition to a number of technical papers and special reports (issue-specific assessments). Since the first assessment report (1990), the IPCC has drawn strong conclusions about the (causal) relationship between human-induced emissions of GHGs and a trend of increasing global mean temperatures, although it is fair to say that this attribution of climate change to human sources has been increasingly scientifically substantiated during the course of the process. Thus, rather than progressing by sudden scientific breakthroughs, the IPCC process has taken the form of a gradual development of the knowledge base towards increasingly strong conclusions about the causal relationship between anthropogenic GHG emissions and climate change.

Climate science, however, is also associated with major points of uncertainty that may not be resolved for quite some time. Accounts of the confidence scientists have in climate model simulations and projections indicate that while scientists consider it virtually certain that the anthropogenic increases in atmospheric GHG concentrations will affect the climate for many centuries, they are uncertain about the precise nature of the response of the climate system, the rate of change, and the attribution of the observed warming trend to anthropogenic increases in the atmospheric concentrations of GHGs (see, for instance, Mahlman, 1997).

As noted, while the US fossil-fuel industry, particularly as represented by ExxonMobil and the GCC, did not accept the problem definition provided by the IPCC, the European-based industry did. The responses of these industries to the IPCC knowledge base vary accordingly. The US-based industry, with the GCC in the lead, tried to influence the development of the knowledge base itself and discredit the scientific authority and legitimacy of the scientists who provided it. It could be argued that 'sceptics' (herein also the oil lobby) have employed increasingly aggressive methods in this endeavour during the course of the IPCC process. The most prominent example of this is the debate that followed in the aftermath of the IPCC's endorsement of the second assessment report. The IPCC's re-editing of this report led to accusations from the GCC of 'scientific cleansing'. ${ }^{19}$ Moreover, in an editorial-page piece in the Wall Street Journal, Ben Santer, who was convening lead author of the most contro- 
versial 'attribution-chapter' of the second assessment report (chapter 8), was held personally responsible for the 'cleansing' ${ }^{20}$ Santer interpreted the incident as 'a skilful campaign to discredit the IPCC, me and my reputation as a scientist'. ${ }^{21}$

These lobbying tactics represented a more aggressive strategy by the coalition. While it certainly served to draw the attention of international media, it also backfired in the sense that it served to alienate some of the GCC's own members. In 1996, Nature reported that 'several GCC member companies are understood to have been uneasy about the organization's aggressive tactics' ${ }^{22}$ For instance, the aggressive lobbying tactics alienated the European-based industry, which acknowledged to a much larger extent the problem definition provided by the IPCC, and accepted the climate problem as a concern that needed to be addressed and taken into account in its operations.

There are at least two possible explanations for these variations. First, they may have been caused by corresponding variations in the companies' access to - and hence influence over - the IPCC process and its conclusions. Second, they may have been caused by company-specific differences in the companies' receptiveness to the knowledge and information provided by the IPCC.

The IPCC is organised in three main, cross-cutting decisionmaking levels: (1) the 'scientific core', which is responsible for producing the actual scientific assessments of each of the three working groups (WGs); (2) the WG Plenaries, at which the IPCC formally endorses the bulk assessment reports; and (3) the highest decision-making level, which is the full Panel Plenary, whose main tasks are organisational and administrative in nature (except for the formal endorsement of a Synthesis Report, in which the main conclusions of the reports from all the three WGs are synthesised).

At WG and Panel Plenary levels, the IPCC is characterised by an unprecedented openness. While it is only national delegates (and scientists, in the endorsement of summaries at WG level) that have formal voting power in the IPCC, all NGOs and intergovernmental organisations (IGOs) accredited within the UN system can participate at IPCC meetings. At these levels, these meetings have never been closed to participants from these categories, but speech restrictions have been enforced at meetings with a tight 
time schedule. The oil industry has participated actively in the IPCC process through a variety of organisations, but the GCC has had a leading role in the orchestration of the lobby's opposition. Variations in access as an explanatory factor for variations in industry responses to the knowledge base provided by the IPCC do not, therefore, have much support in this case. Companies seem to have had equal opportunities to participate in the process.

Company-specific variations in receptiveness to the knowledge provided by the IPCC, however, seem to gain more support in this case as an explanation of variations in industry responses. One indication is the difference between ExxonMobil and Shell in the extent to which the companies themselves conduct research on the areas covered by the IPCC (see also chapter 4 ). This difference is emphasised by officials from both companies. ${ }^{23}$ Exxon has had internal expertise since the early 1980s, and made further investments in R\&D activities in this area during the 1990s. ${ }^{24}$ In contrast, Shell has gradually decreased its R\&D activities over the last couple of decades and has had its own climate expertise only since the very late 1990 s. $^{25}$

The distinction between ExxonMobil and Shell in their internal climate expertise is also reflected in differences in the nature of their participation in the IPCC process. While both Shell and Exxon representatives have participated as observers at IPCC meetings and as reviewers in IPCC assessment reports, only Exxon scientists have participated as cited contributing authors listed in the references of the reports. This indicates that there is a clear difference between the companies in their dependency on IPCC conclusions. While Shell has limited internal climate expertise upon which to base counter-claims, ExxonMobil has a relatively long tradition of climate science and can thus present competing knowledge claims based on their own research (see also Kolk and Levy, 2001).

The success of the GCC strategy in terms of dissuading the new Bush administration from taking on Kyoto commitments should be noted, however. This is reflected in Bush's rhetoric in relation to the US withdrawal. When he rejected the Kyoto agreement, he called it 'fatally flawed', 26 and also reportedly 'questioned what he called the "incomplete state of scientific knowledge behind it"'. ${ }^{27}$ In spring 2002, moreover, events suggest that ExxonMobil 
successfully lobbied the White House to withdraw US support of Robert Watson's continued chairmanship of the IPCC. ${ }^{28}$

The IPCC conclusions thus brought about different perceptions within the fossil-fuel industry on the nature and urgency of the climate problem - with a main distinction running between European and US-based companies. It is important to note that there were no breakthroughs in climate science immediately preceding the strategy changes that could have induced or persuaded the industry to change its strategy.

\section{Regime pressure}

In spite of strong opposition from the fossil-fuel lobby, parties to the UNFCCC succeeded in adopting the Kyoto Protocol - a regulatory framework for international GHG regulation that certainly represented a reinforcement of the more lenient UNFCCC. Moreover, with the adoption of the Buenos Aires Plan of Action at COP-4 in 1998, parties succeeded in institutionalising the continuation of the cooperation even before the details of the agreement had been worked out. Thus, with the Kyoto Protocol and the decisions following in its aftermath, parties succeeded in racking up the international climate regime a notch, as well as in providing institutional feedback mechanisms around which actor expectations converged.

The dynamic these achievements set off, however, took on a completely different form in the US and in Europe. In the US, the agreement backfired and ultimately brought US climate policies back to square one (the UNFCCC level of ambition). In Europe, the adoption of the Kyoto Protocol set off a process through which the stringency, specificity and level of ambition of European GHG regulations were gradually further increased.

The response to the Kyoto Protocol by the US industry is - to some extent - dual. There are indications that parts of the US industry did take initial steps towards a more proactive stance. One example of this is the foundation of the Pew Center on Global Climate Change - a US thinktank - in 1998. The objective of the centre is to educate policy-makers as well as the general public about the causes and possible consequences of climate change and to encourage the domestic and international communities to reduce emissions of GHGs. In 2000, the Pew Center comprised 21 major US companies. Today, the number has risen 
to nearly 40, most of which are included in the Fortune 500. The Pew Center now comprises previous GCC members such as Shell and BP. The problem, however, was that the entire US industry including Pew members - was opposed to the Kyoto agreement. Thus, not even Pew had an explicit position on the Kyoto Protocol, at least not initially.

Moreover, for the other - and as it turned out, the major - part of the US industry, the Kyoto agreement did not induce small steps towards a more proactive stance at all. On the contrary, the industry almost felt betrayed by the US government's consent to the agreement, ${ }^{29}$ and its adoption set off a reinforced mobilisation against it. This strategy was crowned with success when the newly elected Bush administration announced its withdrawal from the Kyoto Protocol in 2001. After this, the international climate regime entered the doldrums.

In Europe, on the other hand, the adoption of the Kyoto Protocol - and the EU's commitment to reduce its emissions by 8 per cent from 1990 levels by 2008-2012 - set off a completely different dynamic. For the EU, the Protocol represented the 'green light' it needed to proceed with its development of climate policy. The direction in which the EU was heading on this issue had been evident for quite some time: towards a fully fledged regulatory framework for GHG emissions abatement. As the EU is a supranational entity, its decisions, in the form of legally binding directives and regulations, have a higher authoritative force than decisions in regular intergovernmental cooperation. Also, EU decisions tend to be linked to stronger verification and compliance systems.

The development of the EU climate regime was gradually delinked from progress (or the lack thereof) in the international arena. The EU worked along two increasingly independent pathways: one that constituted efforts to save and strengthen the international climate regime in order to get other countries at least to do something on climate change (EU as actor); and another that constituted EU implementation of its Kyoto Protocol commitments as if they had already entered into force (EU as regime). As the latter process progressed, it gained its own momentum and gradually became independent - at least temporarily - of the success or failure of efforts along the other pathway.

In June 1998, the EU adopted the renegotiated burden-sharing 
agreement. Thus, both the EU and the member states will have legally binding targets and share the responsibility for meeting them. In March 2002, EU member states agreed to be legally bound by the Kyoto Protocol, and the EU and its member states ratified the agreement in May 2002.

In 2000, the EU established the European Climate Change Programme (ECCP) to 'drive forward EU efforts to meet the targets set by the Kyoto Protocol' (ECCP, 2001: 3). With its multi-stakeholder approach, the ECCP serves both as an instrument for ensuring progress in the implementation of EU climate policies, and as a vehicle for participation by industry in the process. Also, the EU has proposed an emissions trading directive as the core element of the ECCP. In December 2002, EU environmental ministers agreed to create the world's first international GHG emissions trading system, subject to final approval by the European Parliament. The EU has had a monitoring mechanism for its GHG emissions since 1993.

The European-based industry responded to these changes in political framework conditions with an almost unequivocal support of the Kyoto Protocol. In parallel with the development in EU climate policies, a reactive stance on the issue became a less viable option for industries most affected by the EU regulatory framework. At the very least, such a strategy was increasingly associated with a significant risk. Moreover, the risk associated with a proactive strategy was reduced because new markets and opportunities had been developed as part and parcel of the European climate regime. At the same time, this shift in the strategies adopted by the European oil industry further facilitated the EU's drive towards a more ambitious climate policy. The establishment of in-house emissions trading schemes within BP in 1998 and Shell in 2000 acted as key drivers in the EU policy debates (Christiansen and Wettestad, forthcoming). Thus, the relationship between the European industry and EU political authorities had shifted from contentiousness during the fight over the carbon/energy tax in the beginning of the 1990s to a more harmonious situation a decade later, even though there are still different views on specific parts of the ECCP. Currently, the European industry, particularly the oil industry, to a much larger extent represents a partner in the development of EU climate policies - a situa- 
tion particularly evident in the process leading up to the directive on emissions trading.

This dynamic, however, should also be seen in relation to the development of climate policies at the national level. Within the $\mathrm{EU}$, one of the most proactive countries on the climate issue is the Netherlands. As discussed in chapter 5, Shell sees the Netherlands as a 'test country' for what the industry can expect from a viable climate policy. ${ }^{30}$ In 1989, the Dutch government announced its decision to stabilise $\mathrm{CO}_{2}$ emissions at $1989 / 1990$ levels by 1995 at the latest. In 1990, a revised plan called for a 3-5 per cent reduction from average 1989/1990 levels by 2000. The Netherlands was among the first major industrialised countries to ratify the Kyoto agreement. ${ }^{31}$ Simultaneously, policy instruments have been stepped up. Shell, therefore, has operated within a political context that has sent strong signals of future GHG regulations from two levels: the national level in Dutch climate policies and the regional level in EU climate policies.

As framework conditions for industry, the international and EU climate regimes thus have markedly different consequences. In the international climate regime, ambiguity and uncertainty have prevailed - and even increased with the US exit - throughout the regime-building process. In contrast, EU climate policy-making has maintained and even increased its momentum during the last decade, thus sending a strong signal to industry of an emerging regulatory framework on this issue. After a faltering start during the early 1990s, the EU succeeded in providing a leadership role in the climate process during the latter half of the decade. The EU had to admit defeat in persuading the US not to withdraw from the cooperation and mobilised support to 'go it alone'. ${ }^{32}$

\section{Regime opportunities}

The EU climate regime served to create new market opportunities particularly in two areas: the development of a market for renewable energy sources and the development of an internal EU scheme for $\mathrm{CO}_{2}$ emissions trading.

Renewable energy sources In implementing its Kyoto Protocol commitments, the EU has identified a series of energy actions, including a prominent role for renewable energy sources. The development of renewable energy has for some time been a 
central aim of Community energy policy. As early as 1986, the Council listed the promotion of renewable energy among its energy objectives, and with the ALTERNER programme (1992) the Council adopted a specific financial instrument for renewables promotion (COM (97) 599 final).

The first step towards a strategy for renewable energy was the Commission's adoption of a Green Paper in November 1996. In 1997, the Commission adopted a strategy and action plan directed towards the goal of having renewable energy sources cover 12 per cent of the EU's gross inland energy consumption by 2010 (COM (97) 599 final). In its decision of 28 February $2000,{ }^{33}$ the European Parliament decided to extend the ALTERNER programme in the establishment of ALTERNER II as a 'specific programme for promotion of renewable energy sources'. The financial framework for the implementation of the programme for the period 1998-2002 is set at EUR 77 million. Both UNICE and EUROPIA support the EU's investments in renewable energy.

The long history of the renewables policy within the European Community has been marked by financial setbacks (see Wettestad, 2001). Nevertheless, ALTERNER and particularly the establishment of a financial mechanism in 1992 are an indication of a political effort to develop a market for renewables in Europe (see Ikwue and Skea, 1994). This may have been the political signal the European-based oil industry needed to initiate its own investments in renewable energy. There is thus a noteworthy coincidence between events taking place on the policy side during this period and events within the European-based oil industry. The change in BP's position on the climate issue, for instance, is remarkably parallel with the Green Paper issued by the Commission in 1996, where the 12 per cent target on renewable energy sources was tentatively suggested. Similarly, the following White Paper, where the 12 per cent target was adopted, parallels Shell's establishment of a fifth core business area - Shell International Renewables - in 1997.

Again, however, the relationship between the EU and Shell should be seen in the light of the development of renewables in the Netherlands (see also chapter 5). In 1995, the Netherlands adopted a target of renewable energy sources attaining a 10 per cent share of total energy consumption by 2020 . Over the past 
few years, policies to promote renewables have been strengthened by the introduction of a wide range of fiscal arrangements, such as fiscal tax credits. Renewable energy is also promoted through its inclusion in the long-term agreements (VROM, 1999). Thus, Shell was subjected to 'double exposure': both the Dutch and the EU renewables targets directly influenced its decision to establish its fifth core business area in 1997 (Skjærseth and Skodvin, 2001).

These developments may not, however, have been enough to push the industry from a reactive to a proactive position. They do indicate, though, that there were movements in the industry's position even before the adoption of the Kyoto Protocol. The actual adoption of the Protocol may have been the crucial factor that tipped the balance, pulling the industry towards a more proactive strategy.

The European emissions trading scheme Another central component of EU implementation of its Kyoto Protocol commitments is the internal EU scheme for emissions trading. In June 1998, the Commission stated that 'the Community would set up its own internal trading regime by 2005 ', three years prior to the operation of an international trading regime (cited in COM (2000) 87 final: 10). As noted, the Council of Ministers has agreed on the proposal for an EU directive on a regulatory framework for GHG emissions allowances within the Community (COM (2001) 581 final).

The emissions trading scheme was prepared in accordance with the ECCP's multi-stakeholder approach. Thus in September 2001, a stakeholders' consultation meeting was convened that included all major business and industry organisations - such as UNICE, the European Roundtable of Industrialists and EUROPIA - as well as representatives of the environmental movement. The Summary Record of the meeting reveals a broad-based consensus on the main issues, including an overwhelming majority in favour of going ahead with emissions trading sooner rather than later, and a general agreement on a mandatory scheme from 2008.34

The number of installations covered by the EU emissions trading scheme proposal are limited to some 4,000-5,000 cover- 
ing about 46 per cent of (total) $\mathrm{CO}_{2}$ emissions of the $15 \mathrm{EU}$ member countries in 2010. Refineries are included in the core activities, thus making the oil industry an important target group. The change in the position of EUROPIA illustrates the significant shifts that took place within the European oil industry after the Kyoto Protocol. EUROPIA is composed of 21 oil companies and represents the downstream activities (including refineries) of the oil industry within the EU institutions. In the early 1990s, EUROPIA was, as discussed earlier, one of the most aggressive opponents of EU climate policy, particularly the carbon/energy tax. Today, EUROPIA welcomes the EU emissions trading directive as a learning exercise towards an international system under the Kyoto Protocol. In general, EUROPIA supports UNICE's position on climate change (EUROPIA, 1999). And UNICE supports the proposed EU directive as a 'learning-by-doing' process in the period before 2008. In a detailed position paper on the EU proposal, UNICE has no comments on mandatory monitoring, reporting and verification requirements. With respect to enforcement, UNICE supports financial penalties, but proposes to change the wording in the directive to avoid unnecessary uncertainty (UNICE, 2002).

There are at least two closely related reasons underlying the change in the position of EUROPIA: changes in the climate policy of the EU and its member states, and changes in the strategies of Shell and BP particularly. ${ }^{35}$ With respect to the former, the prospects of a stringent internal EU scheme for emissions trading from 2005 sent a strong signal to industry that a new market for $\mathrm{CO}_{2}$ was emerging and that industry should prepare itself. And with respect to changes in Shell and BP, the parallelism in the Green Paper issued by the Commission on the design of an emissions trading system and Shell's launching of its own internal emissions trading system (STEPS) - both events taking place in 2000 - is interesting. These policy measures serve to generate new market opportunities and may decrease costs of emissions reductions. It is illustrative, for instance, that BP's three-year-old emissions trading system yielded $£ 650$ million in extra value for the company. 36

EUROPIA also includes US companies operating in Europe, such as Texaco-Chevron, Conoco, Phillips and ExxonMobil. In fact, ExxonMobil has a leading role within EUROPIA even on 
environmental matters. ${ }^{37}$ This shows that EUROPIA's position is determined by the corporate leaders in this field and not the lowest and most powerful denominator.

\section{Conclusion}

In this chapter, we have shifted our focus from the domestic level of the DP model to the international level of the IR model. The main contribution of the latter is that it allows for a stronger focus on the dynamic relationship between corporate strategy and international institutional development and thus serves to improve our understanding of changes in corporate climate strategy choice. In particular, two questions remained unanswered from our analysis in the preceding chapters. What caused Shell's turnabout from a reactive to a proactive strategy in 1997/1998? And why did ExxonMobil not modify its reactive strategy in response to its apparent lack of influence resulting in the US signing of the Kyoto Protocol in 1997?

Recalling our discussion in chapter 2, we assumed that the extent of influence corporate actors have on international regimes constitutes an important determinant for corporate strategy choice. Corporate influence is at least linked to three factors: (1) the cohesion of the industry group and its ability to act in a unified manner; (2) the strength of counterbalancing forces, in particular ENGOs; and (3) the decision-making procedures applied and the group's access to central decision-making processes. If a reactive industry exercises a strong influence and largely controls the development of the regime, a persistent reactive strategy can be expected. In contrast, if the industry has a weak influence and the regime 'matures', we can expect a change towards a proactive strategy.

Our analysis shows that neither the emerging dissolution of the oil lobby nor a change in the influence of the green movement can provide satisfactory explanations for the loss of industry influence on international climate commitments from 1992 to 1997. Rather, the decreased influence of the fossil-fuel industry preceding the adoption of the Kyoto Protocol was caused by a number of factors: a change in industry access at the governmental level in the US; a change in EU climate policy from taxes to burdensharing, renewables and flexible mechanisms; and a change in 
decision rules within the EU. The adoption of the Kyoto Protocol, moreover, became the precursor to the emerging US-EU divide in both climate policies and industry strategies. The European-based industry shifted from a reactive to a more proactive strategy in response to EU regulatory pressure and new market opportunities, on the basis of what was perceived as a persuasive knowledge base.

In the run-up to the UNFCCC, the industry exerted a strong influence on the development of the climate regime, indicated by the match between industry interests and the joint commitments of the regime: the UNFCCC reflected the interests of the fossilfuel industry at large, particularly in the sense that no legally binding reduction targets and timetables were included. During this phase, the fossil-fuel lobby, constituted by both Europeanand US-based companies, represented a cohesive and unified coalition. This exerted a relatively strong influence on the climate regime, but primarily at the national and regional levels. As we have seen, the US industry influenced the design of the US position at the UNFCCC negotiations, and the European industry contributed to block the adoption of the carbon/energy tax, thus crippling EU attempts to perform a leadership role at the UNFCCC negotiations. Thus, the industry had a high capacity for blocking progressive national climate negotiating positions, and the coalition maintained a reactive strategy.

With the adoption of the Kyoto Protocol five years later, however, the situation had changed. The Kyoto Protocol went far beyond the industry's interests, particularly in terms of the inclusion of specific reduction targets and timetables, and the exclusion of commitments for developing countries. During this phase the influence of the industry on the regime development was (temporarily or permanently) reduced and the regime had a stronger impact on the strategies of the industry - at least in Europe. The agreement was adopted quite contrary to the interests of the fossil-fuel industry and despite vigorous attempts, particularly by the US-based companies, to stop it. The European industry - including Shell - revised its strategy in response to a situation where its capacity to influence the climate position of the EU was significantly reduced. As we have seen, the European industry moved towards a more proactive strategy after the adoption of the Kyoto Protocol. 
In the US, the Clinton-Gore administration excluded the fossilfuel lobby from the decision-making process preceding and during the Kyoto negotiations. The exclusion was temporary, however, since the fossil-fuel industry maintained its influence through the Byrd/Hagel resolution and its alliance with Congress. This contributes to explaining why the US industry did not shift its strategy towards a more proactive approach in response to the adoption of the Kyoto Protocol. For the agreement to be ratified by the US and become US law, it had to acquire support by a twothirds majority in Congress. Thus, ExxonMobil was convinced that the US would never ratify the Kyoto Protocol, maintained its reactive stance and escalated its mobilisation against the agreement. Thus the influence of the US-based industry remained unaltered, despite the temporary setback during the Kyoto negotiations, and has largely maintained its reactive approach to the climate problem.

Until quite recently, most observers considered an international climate regime without the participation of the US to be highly unrealistic. With its 25 per cent share of global GHG emissions, the US is a pivotal actor in global efforts to abate the climate problem. Thus, the US fossil-fuel lobby had every reason to believe that the country's withdrawal from the Kyoto agreement would sink the international effort to regulate GHG emissions. With the EU's apparent success in mobilising sufficient support for the Kyoto agreement to enter into force even without US participation, the US fossil-fuel lobby did not sink the agreement, although its influence has affected the inclusiveness of the regime.

After Kyoto, the fossil-fuel lobby is no longer a cohesive interest group in the negotiations, and European- and US-based companies face significantly different regulatory frameworks. In essence, the IR model is supported by the observation that the climate strategies of Shell (and the European fossil-fuel industry) and ExxonMobil (and the US fossil-fuel industry) correspond to their respective influence on the climate regime.

As it turned out, the adoption of the Kyoto Protocol was a precursor to an emerging divide between Europe and the US, in terms of both policy measures and corporate strategy. Regimes may start out with a narrow scope and lenient commitments, but as long as they include feedback mechanisms around which actor 
expectations converge, a dynamic development is encouraged. As discussed in chapter 2, we believe the combination of the 'snowball effect' at the regime level and the sovereignty principle is a key mechanism whereby international regimes can induce change in corporate strategies. The principle of sovereignty provides states with significantly more rights than large corporations. In particular, sovereign states have the right to refrain from international agreements that they have not given their consent to. Corporations do not have this right. Thus, when states choose to join international regimes that become progressively more 'demanding', the decision environment for large corporations also changes. With the EU ratification of the Kyoto Protocol, the framework conditions for the European fossil-fuel lobby became different from those of the US-based industry.

Our analysis has focused on three causal pathways through which the international regime may affect corporate strategy choice: knowledge, pressure and opportunity. All of these mechanisms seem to have been in operation. First, the knowledge-based pathway is linked to the industry's acceptance of and response to the knowledge base provided by the IPCC. While the US fossilfuel lobby has based its reactive position on a refutation of IPCC conclusions, the European oil industry accepts these conclusions as authoritative climate knowledge. As we have seen, the IPCC is organised in a manner that ensures equal access to the process for all stakeholders. The main difference between the European and the US-based industries, therefore, lies in their receptiveness to the knowledge provided. While ExxonMobil has its own research capacity on climate science, Shell does not and is thus more dependent upon IPCC conclusions. It is important to note, however, that factors linked to the gradually evolving knowledge base cannot explain the rapid change that took place in European industry strategies. That is, there were no breakthroughs in the knowledge base immediately preceding, for instance, Shell's strategy shift that could have induced or persuaded Shell to move from a reactive to a proactive climate approach.

Second, we have seen that the climate policy of the EU exerted an increasingly strong regulatory pressure. In chapter 2, we assumed that a strong regime would promote proactive corporate responses by shaping mutual expectations about the need for future regulation. With the 1998 burden-sharing agreement, both 
the EU and each member state have legally binding targets and share the responsibility for meeting these. The ECCP, combined with a monitoring mechanism that has been in place since 1993, has further promoted EU implementation of its Kyoto commitments. Within this regulatory framework, it was increasingly risky for the European industry to adopt a reactive response.

Third, this development was reinforced by the new opportunities the EU climate regime ensured in its policies for promoting renewable energy resources and in the development of an internal scheme for emissions trading. As noted above, there is a noteworthy correspondence, first, between the EU's adoption of the 12 per cent target on renewable energy sources and Shell's establishment of its fifth core business area - Shell International Renewables - and, second, between the Green Paper issued by the Commission on the design of an emissions trading system and Shell's launching of its own internal emissions trading system (STEPS).

In Europe, therefore, climate policies were characterised by a common understanding of the climate problem upon which increasingly authoritative and ambitious measures to implement EU Kyoto commitments were based. In addition, new business opportunities were generated. Concurrent with these developments we see a remarkably quick transformation of most, if not all, European-based oil companies from their reactive stance towards a more proactive approach from which they explicitly express their support for the Kyoto Protocol.

It is also important to note, however, that these factors operate in combination with equally authoritative regulatory measures at the national level, in the companies' home-base countries. The home-base country of the Shell Group, for instance, the Netherlands, has adopted an ambitious climate policy since the early 1990s and was among the first countries to ratify the Kyoto Protocol. The Netherlands, moreover, has also adopted a progressive policy to increase the share of renewable energy sources in national energy consumption. Thus, Shell has been subjected to 'double exposure'. With limited options to influence and block progressive and ambitious climate policies and negotiating positions at either level, this situation has significant implications for Shell's strategy choice.

In sum, our analysis indicates that the extent to which corpo- 
rate actors can influence an international regime indeed has an impact on their strategy choice. A high degree of influence tends to pull the industry towards a reactive approach, while a low degree of influence tends to pull the industry towards a more proactive response at least when combined with regime 'maturation'. Moreover, our analysis indicates that in a situation where the industry has limited influence, international regime features linked to the provision of a common knowledge base, regulatory pressure and new market opportunities seem to constitute important factors for understanding the dynamics of corporate strategy choice.

\section{Notes}

1 Personal communication with Phillip Cooney, American Petroleum Institute, and William O'Keefe, Solutions Consulting, Washington, DC, March 2000.

2 International Environmental Reporter, 30 July 1991, p. 421: 'Oil industry presents paper to Commission opposing creation of tax on energy sources'.

3 Personal communication with Glenn Kelly and Eric Hold in the Global Climate Coalition, Washinton, DC, March 2000.

4 Planet Ark, 9 November 2000, 'Global warming business group cools its message'.

5 Personal communication with Brian P. Flannery and Gary F. Ehlig, ExxonMobil Corporation, Irving, Texas, March 2000; Phillip Cooney, American Petroleum Institute, and William O'Keefe, Solutions Consulting, Washington, DC, March 2000; Glenn Kelley and Eric Hold, Global Climate Coalition, Washington, DC, March 2000.

6 Personal communication with representatives of ExxonMobil, API, GCC and the Pew Centre, in Dallas, Texas, and Washington, DC, March 2000.

7 Personal communication with Brian P. Flannery and Gary F. Ehlig, ExxonMobil Corporation, Irving, Texas, March 2000.

8 Personal communication with Phillip Cooney, American Petroleum Institute, and William O'Keefe, Solutions Consulting, Washington, DC, March 2000.

9 ENDS Environment Daily, 1152, Wednesday 6 February 2002, pp. 2-3, 'Anti-Kyoto business lobby "Deactivates"'.

10 Climate Action Network (CAN), November 2000, COP-6 position paper. Source: www.climnet.org. 
11 Just as the fossil-fuel lobby allied with OPEC countries, ENGOs allied with the parties most vulnerable to climate change. For example, Greenpeace and the Foundation for International Law and Development (FIELD) have strengthened the position of the Alliance of Small Island States (AOSIS).

12 FoE, 1992, 'The carbon/energy tax and industry: exploding the myths'.

13 One important weakness referred to is the lack of targets. See 'Emissions trading in the EU: let's see some targets!', 20 December 2001. Source: www.climnet.org.

14 Personal communication with Phillip Cooney, American Petroleum Institute, and William O'Keefe, Solutions Consulting, Washington, DC, March 2000.

15 Personal communication with Phillip Cooney, American Petroleum Insitute, and William O'Keefe, Solutions Consulting, Washington, DC 2000.

16 Personal communication with Phillip Cooney, American Petroleum Institute, and William O'Keefe, Solutions Consulting, Washington, DC, March 2000.

17 The most important were: (1) the incorporation of six GHGs instead of three; (2) inclusion of sinks; (3) multi-year targets instead of single-year; and (4) a market-based approach allowing for emissions trading.

18 Interview with Eileen Claussen and Sally C. Ericsson, the Pew Center on Climate Change, Washington, DC, March 2000.

19 E. Masood, 'Climate report "Subject to scientific cleansing", Nature, 381, 13 June 1996, p. 546.

20 Wall Street Journal, 12 June 1996. See also Bulletin of American Meteorological Society, 77: 9, September 1996, pp. 1961-6, where all the correspondence in The Wall Street Journal on this occasion is reprinted. For a more detailed account of this incident, see Skodvin, 2000b: 215-19.

21 E. Masood, 'Climate report "subject to scientific cleansing"', Nature, 381, 13 June 1996, p. 546.

22 E. Masood, 'Companies cool to tactics of global warming lobby', Nature, 383, 10 October 1996, p. 470.

23 Personal communication with Brian P. Flannery and Gary F. Ehlig, ExxonMobil Corporation, Irving, Texas, March 2000; Gerry Matthews, Shell International, Washington, DC, March 2000.

24 Personal communication with Brian P. Flannery and Gary F. Ehlig, ExxonMobil Corporation, Irving, Texas, March 2000.

25 Personal communication with Gerry Matthews, Shell International, Washington, DC, March 2000. 
26 'Remarks by President Bush on global climate change', 11 June 2001. Source: www.state.gov/g/oes/rls/rm/4149.htm (accessed 8 March 2002).

27 Planet Ark, 5 April 2001: 'ANALYSIS: Bush's climate stance cheers scientific sceptics'.

28 Los Angeles Times, 4 April 2002: 'Charges fly over science panel pick'. Source: www.latimes.com (accessed 8 April 2002); Guardian, 5 April 2002: 'Oil giant bids to replace climate expert'. Source: www.guardian.co.uk (accessed 5 April 2002).

29 Personal communication with Phillip Cooney, American Petroleum Institute, and William O'Keefe, Solutions Consulting, Washington, DC, March 2000.

30 Interview with Barend van Engelenburg, Ministry of Housing, Spatial Planning and the Environment, The Hague, November 2000.

31 Planet Ark, 4 March 2002: 'Dutch set pace on Kyoto treaty ratification'.

32 European Commission, Briefing Paper, 6 July 2001: 'EU position for the Bonn conference on climate change 19-27 July 2001.' Source: europa.eu.int/comm/environment/climat/eupositions.htm.

33 'Community legislation in force, Document 300D0646: Decision No 646/2000/EC of the European Parliament and the Council of 28 February 2000 adopting a multiannual programme for the promotion of renewable energy sources in the Community (Alterner) (1998 to 2002)'. Source: europa.eu.int/eur-lex/en/lif/dat/2000/en_300D0646. html (accessed 25 February 2002).

34 EU Commission, 14 May 2001: 'Green Paper on greenhouse gas emissions trading within the European Union. Summary of submissions. Part I: Non-governmental submissions.'

35 Interview with Valèrie Callaud, EUROPIA, Brussels, November 2000.

36 Planet Ark, 22 February 2002, 'Emissions trading systems developing as patchwork'.

37 ExxonMobil has the highest share of representation in the Secretariat General and the Board of Directors in EUROPIA, and leads EUROPIA sections on air quality, industrial sites and environment. 